\title{
Computational Thinking and MOOC - Oriented Computer Courses Teaching Mode for Non-Computer Major
}

\author{
Qian Gao \\ School of information Qilu University of Technology Jinan, Shandong Province, China
}

\begin{abstract}
Non-computer major students in the future are required to master new computer methods to support different subjects' research. In order to make the computational thinking fuses with the thinking of other subjects, and promote the formation of all students' creative thinking, this paper comes up with the teaching problems of the existing non-computer majors about the setting of teaching content, teaching pattern, teaching methods and teaching tools, and then proposes five reformation schemes. The traditional "teaching method/studying method" is tools oriented, while this paper puts forward a novel teaching model which can completely change the traditional teaching approach to computational thinking oriented blending learning, flipped class and cooperative learning model. Furthermore we use the independently developed MOOC (Massive Open Online Courses) platform and the MOOC classes involved with teachers and students, aiming at training students' computational thinking to realize the flipped class. One-year practice result shows that the proposed teaching model can turn the main teaching objective to making students achieve computing thinking skill from traditional prescriptive teaching and to create a basic computer technology educational class system which takes the computer science theory, knowledge application, basic skill as foundation, takes computational thinking as principle line and takes the information application skills as goal.
\end{abstract}

Index Terms -Computational Thinking. MOOC Platform. Flipped Class. Independent Study.

\section{Introduction}

With the extensive application and great population of computer and Internet, also with the improvement of undergraduate freshmen's computer skills, the series of computer basic courses for non-computer major students are facing severe crisis, which are doubted by non-computer professional and computer professional scholars. The core of crisis and query is that what is the necessity and core value of this series of computer courses' existed. Crisis and query are phenomenon, but the essence is that the great gap between training ability or developing intellect under current teaching model and need of computational thinking or computational ability in the future, as shown in Fig.1.

The series of university computer courses, as basic courses on computer set up for students in Institutions of High Education, aim to instruct the students in pursuing a series of extensive learning, practice and research on the basis of grasping correlative computer concepts, and to meet requirements of their basic quality from an information-based society by developing their innovative consciousness, thinking on computer application and the computing ability to solve practical problems. However, the current teaching model only enables students to acquire knowledge and skills, but fails to stride over the large gap to apply the common computing means to the specialized ones in various disciplines. Meanwhile, many problems remain in teaching content, teaching model, teaching methods, and teaching means.

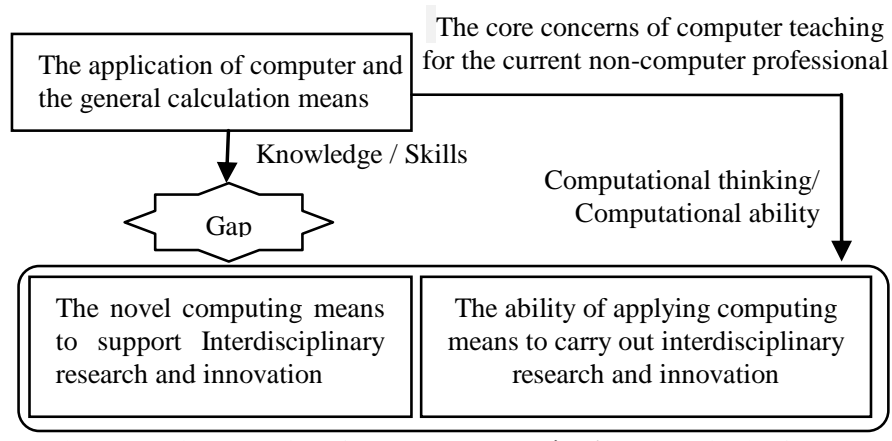

The computing capacity of non-computer majors' students in the future

Fig.1. The gap between "Knowledge / skills" teaching and "thinking/ability" requirement

1) 'The theory of Special tool": Over a long time, people have made a mistake on the understanding for the Computer Foundation Class. They think Computer Foundation Class is to teach learners how to use computer. Therefore, forming "the theory of special tool" for they use the computer as a tool. The consequence is that students who have been trained only master the knowledge and skills of the computer, but they can't apply computer to realize interdisciplinary studies and innovation, and also don't have the ability to use the innovative thinking to solve the practical problems.

2) The teaching materials can't keep up with the updated knowledge: The contents of the textbooks are very obsolete which has a big gap with the international advanced level. Besides, the current teaching pattern absolutely depends on the class which has imprisoned students in the textbooks. It is failed to take full use of high quality resources inside and outside the university.

3) The contradiction between "expansion of knowledge" and "compression of the teaching hours": The teaching hours of computer course has been compressed constantly because that the result of balancing the "less teaching and more exercise" "basic and professional" in colleges-teaching reform. So it is worthwhile to think about "how to choose the course content reasonably " and "how to teach the course content scientifically and efficiently".

4) The mode of theory teaching is outdated: the major ways to teaching in classes in many colleges and universities 
are the application of multimedia presentation level. The classroom teaching under the background of information in colleges and universities is evolved from "taught by teacher" to "taught by machine", the teachers become megaphone which transfer bitty static knowledge while the students become container who are used by holding they get from their teachers, students are lack of initiative consciousness of interaction and also lack of the interaction between teachers and students. The back feed of teaching information are onesideness, hysteresis and passivity, these shortcoming kill the enthusiasm, initiative and creativity of the students' studying.

5) The ideas and methods of practice teaching are backward: At present, we only pay attention to the result of practice teaching and ignore the practice process and overlook educating student's application abilities of creating. Moreover, in practical computer courses, the teacher only teach related theoretical knowledge in classroom, and students finish the practice in computer lab by themselves. This kind of teaching method cannot fully mobilize the students' practice enthusiasm and initiative of. Thus, both of teachers and students just pay little attentions to the computer practice teaching.

For above problems, the existing theories and the modes of practice teaching are difficult in crossing the gap which from general calculation means to the professional calculation means of every subject. However, the new idea of computational thinking and the appearance and large-scale application of MOCC Course Platform brought hope for crossing this gap.

Ref. [1] points out, " University education cannot be limited to the basic knowledge instruction, but also develop students' pursuit of science from the learner's rational thinking, making students have a noble personality. As the core idea in the computer course, computational thinking is an effective means to provide a unique way of thinking and solve the problems of one's major." At the same time, computer foundation course is the carrier to train the ability of computational thinking as university foundation course with the same status with math and English.

"Computing thinking" makes the computer education teaching from the "tools" to "thinking" ability training", and makes the computer education must have the abilities that are similar to a person who has the abilities about "reading, writing, calculating". Through the training of college students' computational thinking, it makes that the computational thinking fuses with the thinking of other subjects, and thus, it will promote the formation of all students' creative thinking; Ref. [2] shows that, as a new supplementary means of classroom teaching, the large-scale application of MOCC course platform further embodies the needs of students themselves and social reality, reflects the orientations of the educational value of the self-directed learning and lifelong learning, and speeds up the process of the advanced-computer education's popularization and internationalization. MOCC is not only the improvements of the teaching's techniques and methods in the age of Internet, but also a double revolution about "learning" and "teaching".
Ref. [3] points out, Tsinghua Education Online (THEOL) network teaching comprehensive platform with independent intellectual property rights is a multi-systematic, multi terminal learning environment that supports to adapt to the ubiquitous learning mode, bases on a variety of learning theories (behaviorism, cognitivism, constructivism, connectivism etc.), applies various teaching modes ( teaching, inquiry , task, case type and cooperative type etc. ), faces various educational types (basic education, vocational and higher education etc.). Moreover, how to integrate the universal thinking of computing subject into the training of creative thinking of each disciplines' students, how to make use of the advantages of the MOOC online education to play the role of opening high quality educational resources, how to work along both lines in the classroom and after-school to revolutionize the educational ideas and teaching modes of computer foundation course in the institution of higher learning, to meet the personalized demand of learning, collaborative learning and flipped classroom, to conform to the development tendency of higher education in the information age and the learning modes of students, also to improve the quality of classroom teaching in colleges and universities. These are worthy of in-depth study in theory and practice.

\section{The Trial Reform Proposals}

Many pervasive thoughts in computer science not only reflect the theory of calculation and computer, but also embody the solving thinking and method which are on the base of computer technology or computer problem, and thus help to foster the innovation of non-computer majors, lay the foundation for carrying on disciplinary study and innovation by using computer means in the future.

\section{A. To Rebuild Scientific Training System of Computational \\ Thinking and Ability for Non-Computer Major Students can not only Train Students to Have "Thinking", but also \\ Make Students "See" and Confirm the "Thinking" can be Realized.}

According to the test grade of the freshmen's computer skill as well as the situation that the secondary colleges held, each college draws out 2 classes as an experimental class (these 2 classes has been composed of students with different levels of computer-based skill respectively), carried out different levels of " $1+1+X$ "college Computer Teaching mode. The first " 1 " is the "Fundamentals of Computer "course (for the science students) or "Fundamentals of IT" course (for the arts students) in the first level; the second " 1 " is the "Network Applications and Information Retrieval Technology "course in the second level.

In the practice of reform, we adopted to teaching mode which applied the computational thinking as the dominant idea. We brought the teaching reform model which for the overall into the specific theories and practical curriculum, while built the related theme websites to support the teaching mode, the structure of the theme websites is shown in Fig.2. 


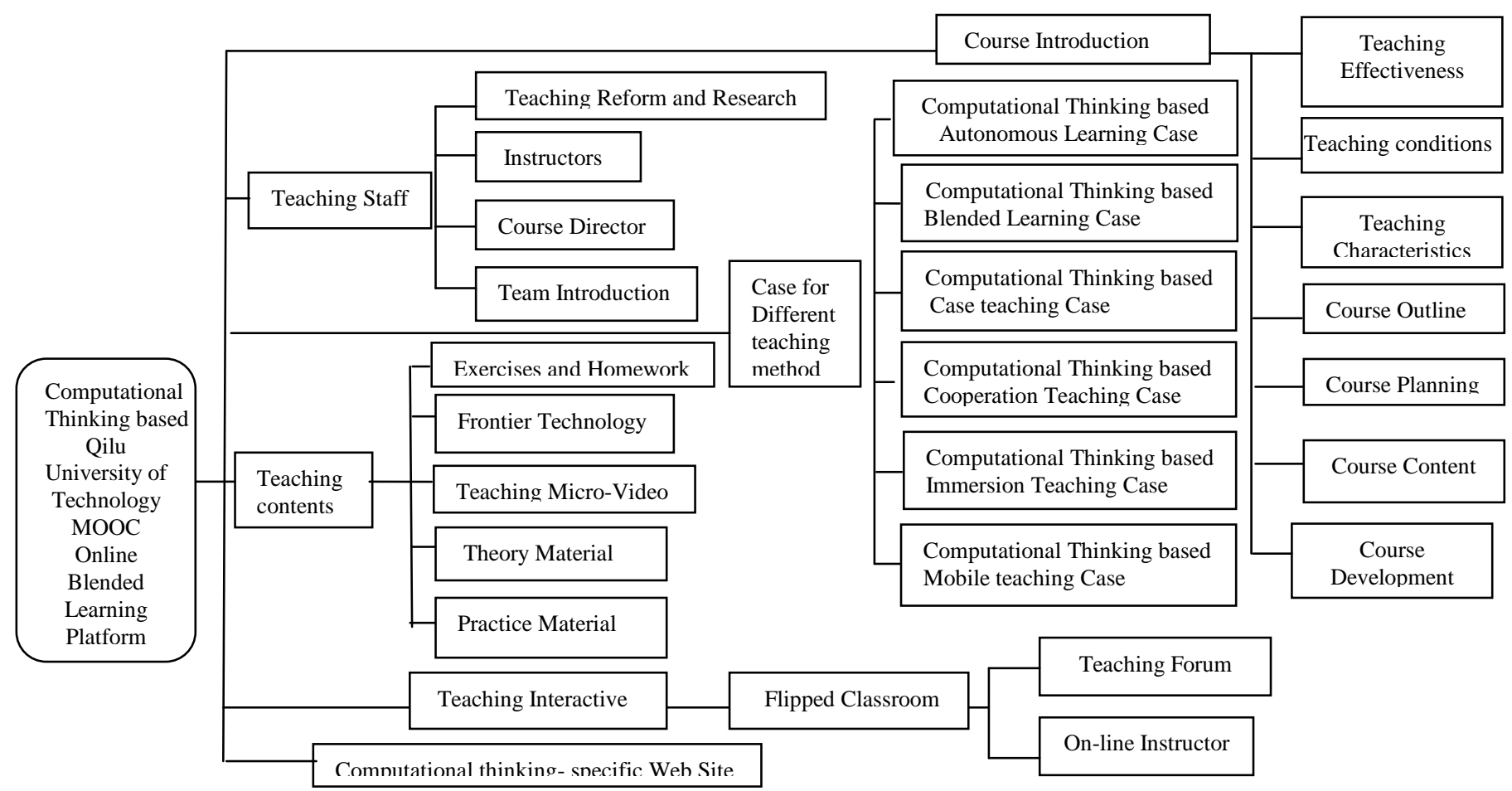

Fig.2. The structure of the theme websites

In theoretical teaching, firstly, to cultivate the students' computational thinking ability by the thought of universal computation platform. To integrate the basic thought which is implied in the computation platform into the blended learning of online and offline by teaching how a computer works and how a program is run is the computer in class; Secondly, to compact the common thinking from the different courses. For non-computer major, due to the limited class hours, computational thinking with universal relevance should be compacted from different courses, such as operating system, database, computer network and so on. Thirdly, to connect different knowledge to form the connectivity thinking, break the barrier between knowledge (such as the differences of the term, different level of abstraction etc.), all these are import to improve the computational thinking ability.

Fourthly, efforts should be made to develop a kind of achievable but non-detail thinking. For one thing, students are able to understand computing thinking and consider this thinking to be realized. The pattern of thinking instead of concrete details can be realized. And finally, a kind of thinking is to cultivate to lay the foundation for developing and applying computing means from various subjects, such as the thought of solving algorithms, computing platform design, a new type of computing platform, etc.

In practice teaching, take the computing thinking cultivation as fundamental task, practical teaching principle and practical programs are designed and all of the non-major computer science students' practical courses are integrated. From the characteristic of automation and abstraction of computing thinking, formalize the partial results of practice teaching reform, so as to gets a template for comprehensive educational reform. During the course of the whole reform in practice teaching, a questionnaire outline is set up to trace and analyze the way of thinking in different students of different courses or different majors, and based on this to develop the computing thinking upon solving the problems, to smooth the reform in practice teaching.

\section{B. To Set up the Teaching Design of College Elementary Computer Courses From the Perspective of Computer Thinking Teaching.}

To make the teaching content topicalize and systematize. Ref. [4] shows that in microcosm, some typical computing thinking teaching content should be organized in the form of specialization such as 'zero and one' 'procedure and process' 'recursion' 'parallel and distributed computing' 'virtualization' 'data abstraction'. Through the typical social phenomenon and its problem solving thinking, it can be deepened into computing problem solving of computing thinking gradually. Focusing on special subjects and through the diversified, vivid and mutual mapping cases, relative thoughts can be expounded. This method can make students understand computational thinking from the shallower to the deeper. It not only prompts the connection between computational thinking and social phenomenon, but also enriches students' imaginative capacity and facilitates the formation of compound thoughts. In macroscopic, using the way of systematization throws light on computational thinking layer-by-layer. For example, first, introduce the basic thought of computed system; next, figure out the answer to the question(arithmetic and system); then, introduce the typical computational thought, such as the typical arithmetic thought, data abstraction, analyzing thought and networking thought and so on. 
C. To Set up the Teaching Mode that Suitable for the Students in Different Professional with Different Levels, and the Training Method to Cultivate The Students' Autonomous Learning and Computational Thinking Ability.

To setup several new teaching and learning models based on the computational thinking and MOOC online platform. Blended learning subvert the traditional mode of indoctrination courses, realize the mixture of learning space, learning resource and learning style, and liberate the students from passively accepting knowledge in the indoctrinating classroom so as to improve their self-learning ability and knowledge construction ability. Case teaching uses case as the drive and cultivates students 'diagnostic reasoning ability through the classroom analysis. Mobile learning makes full use of means of information and communication such as mobile devices to apply the theories like constructivism, connectivism to the formal or informal learning. In the teaching of different majors, it can determine the suitable teaching mode according to the specific practice, and finally realizes the hybrid learning, collaborative learning, and flipping classroom. Teachers can give the classroom explanation by video and other media forms to students and students finish it in extra-curricular time. Class time is mainly used to complete the experiment, class discussion and report discussion. Classroom becomes the teacher-student interaction site to achieve a more flexible, active learning. The method can encourage students' participation, make teachers change from imparting knowledge to the learning guide and facilitator, while students change from the passive reception of knowledge to the active constructor of the significance of the knowledge.

\section{To Establish Teaching Evaluation Criteria for Learning \\ Process and Learning Ability.}

The trial reform proposal adopts new diversified evaluation methods such as self-assessment of students, peer assessment and expert assessment. The teaching evaluation criteria cater to the learning process and ability of students. The proportion of evaluation elements should be made based on the concrete practice as well as students' feedback, and accordingly, criteria like curricula's design and development, teaching organization form and grade certificate can be reformulated. In latter studies, the research will continue to set an effective criterion for students' honesty and integrity during learning.

E. The Adoption of Learning Analysis Techniques on Analyzing Large Amounts of Data and Feedback Information about Learning and Teaching on MOOC can Reflect Students' Learning Conditions and Problems in time, so that it is Conducive for both Teachers and Students to Take Remedies during Learning and for Teachers to Get Support for Flexible Teaching based on Formative Evaluation.

First, by learning analysis technique, learners can effectively locate their learning requirements and support individual learning activity. Then, by learning analysis technique, teachers can implement division in terms of student, aim, teaching, assessment, and student groups for their individual study according to students' individuality and learning requirements. Furthermore, learning analysis technique can provide staff with management and decision evidence. Last, by learning analysis technique, we can trace teaching and learning process in high schools and analyze the influence of all kinds of teaching activity toward teaching and learning. From tracing and analysis, teaching and learning assembled orderliness can be required, and teachers can dynamically adjust methods of teaching and learning according to results of learning analysis. On basis of a large amount of educational data analysis in all respects, teaching has a transformation from disordered individual learning behavior to ordered group and large scale learning behavior.

\section{Conclusion}

This paper analyzes the shortcomings of knowledge / skills-based teaching model and the serious crises faced by college computer courses for non-computer majors, and proposes that computer education of non-computer majors should have a transition from the "tools" teaching to the "thinking" ability. Through the cultivation of computational thinking of college students, we can integrate the calculated thinking and other subjects' thinking, so as to promote education reform programs of students' creative thinking in various disciplines. On this basis, we should regard a computational thinking as the starting point, MOOC courses as an assistant teaching method, and make the pervasive computing thinking into creative thinking among students of all disciplines. In addition, we can also use the internet, exert the effect of high-quality open educational resources, classroom and after-school two-pronged approach, revolutionizing extremely teaching methods of new educational concepts and teaching modes of basic computer course and to meet the students' individual learning needs and enhance the quality of classroom teaching in Universities.

One-year practice result shows that the teaching reform proposals presented in this paper can systematically foster students' ability of using computational thinking means to analysis and solve problems in practice, expand students' application and development ability of their major field and other related field, cultivate students' creative spirit and practical ability, and thus achieve the aim of promoting students' ability in practice and application, and perfecting students' ability in solving various problems.

\section{References}

[1] http://wenku. baidu. com/view/bf7e8bfe910ef12d2af9e7f8. html

[2] Qu Zhenyuan, "Taking the Opportunity of MOOC's Development and Promoting the Deep Fusion of Information Technology and Higher Education ,"China Higher Education Research, vol.6, pp.1-4, 2014

[3] http://www.jyb.cn/high/gdjyxw/201401/t20140104_565729.html

[4] Dechen Zhan and Shunlan Nie, "The basic idea of computational thinking and the reform of the university computer courses," China University Teaching, vol.2, pp.56-60, 2013. 